\title{
Predicting acute kidney injury in severe trauma. A biomarker breakthrough?
}

\author{
Patrick M. Honore*, Rita Jacobs, Inne Hendrickx, Elisabeth De Waele, Viola Van Gorp and Herbert D. Spapen \\ See related research by Stewart et al., http://www.ccforum.com/content/19/1/252
}

We read with great interest the recent article by Stewart et al. highlighting that urinary biomarkers of acute kidney injury (AKI) could identify combat injury patients at high risk of dying or requiring renal replacement therapy (RRT) [1].

According to recent in-depth reviews, the application of biomarkers to predict AKI in critically ill patients is cumbersome at best [2, 3]. Biomarkers have poor discriminative power in heterogeneous patient populations, and levels are significantly influenced by systemic inflammation, pre-existing renal failure, and timing of sampling. Within this context, the study by Stewart et al. is both refreshing and challenging. It focuses on severely injured patients, a fairly well-defined population at substantial risk for developing early AKI $[4,5]$, by using a biomarker panel that consists mainly of upregulated proteins that are most sensitive to detect true histological kidney damage. Whereas the positive predictive value of these biomarkers would argue against urgent evacuation of combat casualties, intensive care unit physicians evidently will adhere an opposite "triage" and invest in a more early and intensive approach of imminent AKI.

The data provided by Stewart et al. also allow a step forward in creating a more performant biomarkerinclusive model (or score?) for predicting the development of AKI in critically ill trauma patients.

A logical next step would be to evaluate the impact of different RRT techniques (e.g., intermittent versus continuous RRT) on morbidity and mortality in this population.

\section{Authors' response}

Jonathan A. Sosnov, lan J. Stewart, Kevin K. Chung

We agree with the analysis by Honore et al. on the future of biomarker research. The current method for diagnosing AKI, via changes in creatinine, is clearly inadequate. One reason for this is the significant lag function from the insulting event. This and the other well-known limitations of creatinine as a biomarker resulted in the search for urinary biomarkers. Although our study did not have sufficient power to create a biomarker-inclusive model to clinically predict AKI and its outcomes, our work adds to the literature that argues for its development [1]. Such a model of AKI would give us a context to develop effective treatments and better allow us to power randomized trials. We do not know how to optimally modulate fluid replacement [6]. We do not know the optimal type or timing of RRT [7]. If we could use an inclusive model to diagnose AKI earlier and correlate changes in urinary biomarkers to specific subsequent outcomes, we might be able to design better intervention studies to answer these important questions.

\footnotetext{
* Correspondence: Patrick.honore@az.vub.ac.be

Intensive Care Unit Department, Universitair Ziekenhuis Brussel, Vrije

Universiteit Brussel, 101, Laarbeeklaan, Jette, Brussels 1090, Belgium
}

C Biomed Central (c) 2015 Honore et al. Open Access This article is distributed under the terms of the Creative Commons Attribution 4.0 International License (http://creativecommons.org/licenses/by/4.0/), which permits unrestricted use, distribution, and reproduction in any medium, provided you give appropriate credit to the original author(s) and the source, provide a link to the Creative Commons license, and indicate if changes were made. The Creative Commons Public Domain Dedication waiver (http://creativecommons.org/publicdomain/zero/1.0/) applies to the data made available in this article, unless otherwise stated. 


\section{Abbreviations}

AKI: acute kidney injury; RRT: renal replacement therapy.

\section{Competing interests}

The authors declare that they have no competing interests.

Published online: 26 December 2015

\section{References}

1. Stewart IJ, Glass KR, Howard JT, Morrow BD, Sosnov JA, Siew ED, et al. The potential utility of urinary biomarkers for risk prediction in combat

casualties: a prospective observational cohort study. Crit Care. 2015;19:252

2. Honore PM, Jacobs R, Joannes-Boyau O, Verfaillie L, De Regt J, Van Gorp V, et al. Biomarkers for early diagnosis of AKI in the ICU: ready for prime time use at the bedside? Ann Intensive Care. 2012;2:24.

3. Vanmassenhove J, Vanholder R, Nagler E, Van Biesen W. Urinary and serum biomarkers for the diagnosis of acute kidney injury: an in-depth review of the literature. Nephrol Dial Transplant. 2013;28:254-73.

4. Bagshaw SM, George C, Gibney RT, Bellomo R. A multi-center evaluation of early acute kidney injury in critically ill trauma patients. Ren Fail. 2008;30:581-9.

5. Podoll AS, Kozar R, Holcomb JB, Finkel KW. Incidence and outcome of early acute kidney injury in critically-ill trauma patients. PLoS One. 2013;8:e77376.

6. Nadeau-Fredette AC, Bouchard J. Fluid management and use of diuretics in acute kidney injury. Adv Chronic Kidney D. 2013;20:45-55.

7. KDIGO. Clinical Practice Guideline for Acute Kidney Injury. Kidney Int Suppl. 2012;1-138. 